Results HIV-infection was found in 208 patients, (7 women, 14 heterosexual men, 187 MSM (18 of whom bisexual); 120 $(58 \%)$ had a non-Western migratory background. Nineteen (9\%) turned out to be known HIV-positive: 17 of those were in care, 2 were referred again. Of 189 newly diagnosed, 172 (91\%) were directly referred by the CSH to a HTC of whom 95\%(163/172) entered care. Median T1 decreased from 9 to 6.5 days and median T2 decreased from 8 to 5.5 days respectively in 2015 and 2018. Linkage to care was 86\%(163/189), 14\%(26/189) were lost to follow-up: 7 went abroad, 10 were untraceable, 8 were referred but did not enter care and 1 could not be verified. Linkage to care was lower for those with a non-Western migratory background compared to Western $(79 \%(83 / 105)$ vs 95\% (80/84); p=0.002).

Conclusion By a close collaboration between CSH and HTC we were able to improve linkage to care to $86 \%$ of new patients, we also observed a decrease in time to care. However, there is a worrisome loss to follow-up, especially in patients with a migratory background. Reasons for loss to follow-up will be investigated, peer involvement may facilitate linkage to care.

Disclosure No significant relationships.

\section{P308 TIMING OF INITIATION OF HIV TREATMENT AND LEVEL OF ADHERENCE AMONG PREGNANT WOMEN UNDER OPTION B+ PROGRAMME IN NIGERIA}

${ }^{1}$ Olumuyiwa Omonaiye*, 'Pat Nicholson, ${ }^{2}$ Snezana Kusljic, 'Elizabeth Manias. 'Deakin University, School of Nursing and Midwifery, Melbourne, Australia; ${ }^{2}$ The University of Melboune, Department of Nursing, Melbourne, Australia

10.1136/sextrans-2019-sti.421

Background Nigeria has the highest rate of mother-to-child transmission (MTCT) of HIV in the world. Adherence to antiretroviral therapy (ART) is therefore crucial in pregnancy because missed doses may lead to virological failure and increased risk of MTCT. Research has shown that ART commenced before pregnancy and continued throughout the prenatal period is associated with low rates of MTCT. We evaluated ART dose adherence among pregnant women who commenced ART before and after conception under the Option $\mathrm{B}+$ programme in Nigeria.

Methods A standardized survey was used to obtain information about health behaviours and practices associated with ART use among pregnant women in four high-volume HIV treatment centres in Nigeria. A woman was considered adherent if she had not missed her ART dose over a four-day period. Prevalence of self-reported $100 \%$ adherence to ART doses was calculated for the previous four days using the bootstrap technique.

Results The survey had a response rate of $92.6 \%$. Of the 275 women, $34.2 \%$ had commenced ART before conception, while 24.7\%, 36.4\% and 4.7\% started ART during the first, second and third trimester of the current pregnancy respectively. Of women starting ART before conception, 51.1\% (95\% CI: 41.5 to 60.6) were adherent. Of the women who commenced ART after conception, $30.9 \%$ (95\% CI 20.6 to 42.6), 19.0\% (95\%
CI 12.0 to 28.0 ) and $15.4 \%$ (95\% CI 0 to 38.5 ) were adherent in the first, second and third trimester respectively.

Conclusion Adherence was highest among women who started ART before conception and lowest among women who commenced ART during the third trimester. Overall, adherence levels were low. It is essential that ART adherence is improved during pregnancy to fast track the elimination of MTCT in Nigeria. It may be helpful to commence screening for HIV status before pregnancy to facilitate early commencement of ART,if required.

Disclosure No significant relationships.

\section{P309 GOING DEEPER - MSM PEER CLIQUES AND NOT PEER GROUPS PROMOTES BEHAVIOUR CHANGE IN HIV PREVENTION INTERVENTION IN NIGERIA}

${ }^{1}$ Lawrence Ukponahiunsi* ${ }^{*}{ }^{2}$ Alex Okoh, ${ }^{3}$ Flora Oyakhilome. ${ }^{1}$ Edo State Agency for the Control of AIDS (EDOSACA), Civil Society, Benin, Nigeria; ${ }^{2}$ Edo State Agency for the Control of AIDS (EDOSACA), Board, Benin, Nigeria; ${ }^{3}$ Edo State Agency for the Control of AIDS (EDOSACA), Management, Benin, Nigeria

\subsection{6/sextrans-2019-sti.422}

Background Guidelines for combination prevention using the Peer Education Plus model (PEP) for HIV in Nigeria include MSM as a key population to target. Assumptions are that MSM are better reached with HIV services in groups of peers consisting of between $8-12$ individuals without taking into account cliques that could make up these groups and the unfavourable legal environment which influences MSM Clique's within groups. Our study investigated how Nigeria can leverage MSM's behaviour for increased uptake of STI and other HIV prevention services in the face of unfavorable legislations.

Methods The global fund R9 HIV program supported Edo state, Nigeria from July 2015 - December 2017 to provide HIV prevention services to 503 MSM. Beneficiaries were recruited and exposed to the PEP model. Peer education was carried out in groups without considerations for cliques in the first two semesters and implemented within cliques in the third and fourth semesters. By the fifth semester, MSM were allowed to either take up services within a cliques or in mixed groups. Access to HIV Testing Services (HTS) including linkages to treatment sites for STIs and HIV were all provided

Results In the first two semesters, uptake of HTS increased from $50.7 \%$ and $49.1 \%$ respectively to $86.3 \%$ and $79.7 \%$ in the third and fourth semesters and came down to $61.5 \%$ in the fifth semester. The number of $\mathrm{HIV}(+)$ individuals, who completed referrals to STI treatment centres increased from $25 \%$ in the first semester to $66 \%$ in the second semester and then reached and remained at $100 \%$ in semesters $3-5$.

Conclusion MSM are more open to access services in their core cliques as compared to groups. This is probably due to their fear about blackmail.' Our study highlights that MSM peer cliques is preferred for behaviour change interventions and therefore suggests how future interventions should be designed

Disclosure No significant relationships. 